\title{
TECHNOLOGY ACCEPTANCE OF DIGITAL PAYMENT SYSTEM PADA PELAKU UMKM DI KOTA BATAM
}

\author{
Saut Pintubipar Saragih, Nopriadi \\ Universitas Putera Batam, Indonesia, Universitas Putera Batam, Indonesia
}

\section{INFORMASI ARTIKEL}

Diterima Redaksi: august, 2019

Diterbitkan Online: September, 2019

\section{KATA KUNCI}

Technology acceptance model, digital
payment, umkm

\section{KORESPONDENSI}

E-mail:

pipin.sitio@gmail.com, nopriadi.jamil@gmail.com

\section{Latar Belakang}

Nilai transaksi Indonesia berdasarkan data Bank Indonesia pada agustus 2018 terdapat transaksi yang terjadi yaitu 135,812,593 instrumen pembayaran, mesin pembaca yang digunakan adalah 881,108 dan volume transaksi sebesar 297,466,773 dengan nominal 3,9 triliun [1]. Berdasarkan data tersebut pelaku usaha

\begin{abstract}
A B S T R A C T
Transaksi keuangan melalui digital payment di Indonesia tercatat mengalami kemajuan dan adanya pergeseran antara transaksi keuangan tunai, non-cash dan e-money. Dalam Penelitian ini akan dikaji bagaimana pergeseran model pembayaran oleh penjual dan pembeli dengan pembayaran yang berbasis digital payment seperti mobile payment, internet banking, elektronik, dan pembayaran digital berbasis aplikasi. Pengumpulan data dilakukan dengan menggunakan teknik interview serta menggunaka questionnaire sebagai instrumen penelitian dalam mengumpulkan data primer dari seluruh responden. Metode analisis data adalah menggunakan metode perhitungan regresi linier sederhana dan alat pengolahan data menggunakan alat bantu berupa perangkat lunak berupa software spss. Hasil dari pengolahan data yang telah dilakukan menunjukan bahwa pelaku usaha umkm di kota Batam telah menggunakan sistem pembayaran digital dimana gateway pembayaran yang banyak dilakukan adalah melalui mobile payment sebesar $80 \%$, kemudian diikuti oleh internet banking payment, diikuti oleh pembayaran berbasis elektronik dan menggunakan sistem pembayaran berbasis aplikasi. Penggunaan sistem pembayaran digital ini juga telah dilakukan sejak 5 tahun terakhir ini dimana seluruh responden telah menggunakan minimal 1 tahun terakhir dan bahkan sudah 5 tahun terakhir sejak 2019. Data penelitian ini juga menunjukan bahwa variabel penelitian yang digunakan menjelaskan bahwa adanya saling hubungan yang saling mempengaruhi dan memberikan korelasi yang siginifikan. Seluruh hiptotesis yang ditetapkan pada penelitian ini juga diterima. Hasil penelitian ini menyatakan bahwa sistem pembayaran digital oleh pelaku usaha UMKM di kota Batam diterima.
\end{abstract}

harus mampu mendeteksi pergeseran proses pembayaran tradisional ke pembayaran digital ini agar usaha yang mereka jalankan tiak kalah bersaing. Urgensi yang ditekankan pada penelitian ini adalah bagaimana teknologi diterima oleh pelaku usaha UMKM untuk dapat bersaing dengan menyediakan kemudahan dalam hal pembayaran kepada konsumen atau rekan 
bisnis atau stakeholder perusahaan yang terlibat. Hasil penelitian ini pada masa depan dapat dijadikan sebuah informasi yang berharga bagi seluruh pelaku usaha UMKM untuk bersiap-siap melakukan transformasi proses bisnis khususnya pada proses pembayaran yang mana hal tersebut merupakan salah satu faktor kemudahan yang akan diapresiasi oleh pihak konsumen. Data bank Indonesia mendukung fakta pembayaran menggunakan teknologi digital sudah menjadi sebuah trend di Indonesia termasuk di kota Batam yang sudah memiliki infrastruktur teknologi yang mumpuni yaitu dikelilingi oleh kabel optik untuk jaringan internet serta masyarakat kota Batam yang sudah sadar akan perkembangan teknologi. Pertumbuhan akses dan pengguna internet di indonesia merupakan salah satu yang tercepat didunia dengan data saat in menunjukkan bahwa pengguna internet aktif di indonesia adalah 143,26 juta pengguna dimana angka tersebut adalah $54,58 \%$ dari totap populasi penduduk Indonesia pada 2017 [2]. Penetrasi pengguna internet juga diikuti tren penggunaan teknologi informasi khususnya pada sistem pembayaran berbasis dimana sistem pembayaran tunai sudah mulai ditinggalkan oleh pengguna internet dan hal tersebut memunculkan tren baru dalam hal sistem pembayaran atau transaksi keuangan yaitu digital payment. Hal ini juga dimanfaatkan oleh para pelaku usaha atau bisnis mikro kecil dan menengah (UMKM) yang memanfaatkaan kemudahan proses transaksi bisnis atau usaha sehingga meningkatkan efisiensi dan efektifitas dalam proses bisnis yang dimiliki. Industri mikro dan kecil dikota Batam mampu menciptakan lapangan kerja sebanyak 14. 655 pada tahun 2016 sesuai dengan laporan badan pusat statistic kota Batam [3]. Saat ini kota Batam merupakan salah satu kota yang sedang bertransisi dari kota berkembang menjadi kota maju terutama dalam hal ketersediaan infrastruktur teknologi. Pelaku usaha mikro kecil dan menengah di kota Batam saat ini sudah banyak yang menggunakan sistem pembayaran digital namun belum digunakan oleh seluruh pelaku usaha UMKM.

\section{Kajian Literatur}

Usaha mikro kecil dan menengah adalah menyatakan bahwa Usaha kecil mikro adalah suatu unit ekonomi yang melakukan aktivitas dengan tujuan menghasilkan barang/jasa untuk dijual atau ditukar dengan barang lain dan ada seseorang atau lebih yang bertanggung jawab dan punya kewenangan untuk mengelola usaha tersebut. Kewenangan yang dimaksud meliputi kewenangan di bidang kepegawaian, pemasaran, keuangan dan sebagainya. Dalam konsep usaha termasuk unit-unit penunjang atau unit-unit pembantu yang berlokasi terpisah dari kantor induknya. Jadi usaha dapat berupa perusahaan tunggal, kantor pusat/induk, kantor cabang/perwakilan, unit produksi seperti pabrik, atau unit-unit penunjang, dan unit pembantu seperti: gudang, kantor pemasaran, atau kantor tempat melakukan aktivitas perusahaan lainnya yang berlokasi terpisah dari kantor induknya. Industri Sedang (banyaknya tenaga kerja 20-99 orang), Industri Kecil (banyaknya tenaga kerja 519 orang), Industri Rumah Tangga (banyaknya tenaga kerja 1-4 orang) [4].

Undang-Undang Nomor 20 Tahun 2008 dan Permendagri no 8 tahun 2014 yaitu Usaha Mikro adalah usaha produktif milik orang perorangan dan/atau badan usaha perorangan. Usaha Kecil adalah usaha ekonomi produktif yang berdiri sendiri, yang dilakukan oleh orang perorangan atau badan usaha yang bukan merupakan anak perusahaan atau bukan cabang perusahaan yang dimiliki, dikuasai, atau menjadi bagian baik langsung maupun tidak langsung dari usaha menengah atau usaha besar. Usaha Menengah adalah usaha ekonomi produktif yang berdiri sendiri, yang dilakukan oleh orang perseorangan atau badan usaha yang bukan merupakan anak perusahaan atau cabang perusahaan yang dimiliki, dikuasai, atau menjadi bagian baik langsung maupun tidak langsung dengan Usaha Kecil atau usaha besar dengan jumlah kekayaan bersih atau hasil penjualan tahunan.

Sistem pembayaran berbasis elektronik merupakan sebuah sistem pembayaran yang telah dikenal dan telah dilakukan oleh masyarakat dunia sejak berpuluh tahun sejak meledaknya komersialisasi internet. Indonesia telah mengenal sistem pembayaran digital pda decade terakhir yang terbanyak adalah pengguna internet banking (pembayaran berbasis internet yang disedikan oleh bank terkait) [5]. Pembayaran yang dilakukan oleh pengguna menggunakan elektronik disebut sebagai sebuah sistem pembayaran digital. Pembayaran elektronik tersebut dapat berupa perangkat elektronik 
seperti komputer, perangkat mobile seperti smartphone, tablet dan lainnya. Seluruh kegiatan pembayaran yang dilakukan oleh pelaku usaha dan oleh konsumen usaha dilakukan menggunakan infrastruktur yang telah dibangun secara sistematis agar transaksi dapat diselesaikan menggunakan sistem yang telah dibangun [6].

Digital adalah sebuah kata yang memiliki arti yang berhubungan dengan angkaangka untuk sistem perhitungan tertentu berhubungan dengan penomoran (sumber kbbi). Melalui arti dari kata digital tersebut dapat dikatakan bahwa digital payment tidak akan melibatkan bentuk fisik pada transaksi keuangan berbnetuk digital [7]. Digital Payment pada dasarnya merupakan sebuah perkembangan dari sistem pembayaran yang telah berkembang dari system pembayaran sebelum internet menjadi sebuah kebutuhan utama masyarakat. Sistem pembayaran elektronik seperti pembayaran menggunakan automatic teller machine yang sangat banyak digunakan oleh bank. Kebutuhan akan efisiensi dan efektifitas dalam kegiatan transaksi keuangan membuat seluruh proses yang dilakukan menjadi semakin bervariasi.

Beberapa keuntungan yang didapatkan oleh pelaku usaha dengan menggunakan layanan digital payment seperti Pembayaran digital dapat meningkatkan profitabilitas wirausaha dengan membuat transaksi keuangan dengan pelanggan, pemasok, dan pemerintah lebih nyaman, lebih aman, dan lebih murah. Membayar gaji secara digital menguntungkan karyawan dan lebih aman serta lebih efektif biaya bagi para majikan. Pembayaran digital secara otomatis memberi pengguna riwayat kredit dan dengan demikian dapat meningkatkan akses wirausaha terhadap kredit. Pembayaran digital memberi para pengusaha wanita kontrol yang lebih besar atas penghasilan mereka, yang secara potensial menguntungkan seluruh rumah tangga mereka, terutama anak-anak [8]. Dari sisi pengguna ternyata ditemukan bahwa karakteristik konsumen atau masyarakat di kota Batam telah mulai berubah yakni masyarakat kota batam telah mulai menggunakan layanan digital payment [9].

Keberadaan uang elektronik di Indonesia secara hukum juga sudah memiliki ketetapan seperti tertulis pada PBI No. 1817//PBI/2016 tentang perubahan kedua atas Peraturan Bank
Indonesia No.1112//PBI/2009 tentang uang elektronik [10].

Variasi digital payment mungkin akan dibedakan berdasarkan bentuk uang yang ditransaksikan. Menurut beberapa peneliti seperti dikutip oleh achmad dan puspa [11] berdasarka Abrazhevich (2001) yang membagi sistem pembayaran digital berbasis e-money yang menggunakan kartu sebagai penyimpan token yang mana data yang ada pada token, sementara Sahut (2008) merinci sistem berbasis e-money ke dalam tiga kategori yaitu E-wallet, dompet virtual dan uang virtual, Sistem berbasis kartu pintar, cek elektronik, transfer bank, pembayaran mikro berbasis akun.

Sistem pembayaran yang banyak dilakukan oleh pengguna digital payment di Indonesia saat ini adalah bank transfer, internet banking, mobile banking, online store value (seperti paypal dan lain-lain), mobile application (gopay, dan lainlain), pmbayaran via perangkat telephone (ponsel) dan lainnya [12].

Model TAM merupakan model yang dikembangkan oleh seorang peneliti bernama Fred D. Davis, Jr di Massachusets institue technology pada tahun 1985, hingga saat ini model penelitian untuk acceptance model sebuah teknologi informasi perangkat lunak pada umumnya yang diciptakan oleh davis adalah yang paling banyak digunakan dan telah banyak dimodifikasi atau dikembangkan oleh peneliti sesuai dengan keperluan masing-masing penelitian. Beberapa model dan teori telah dikembangkan untuk menjelaskan perilaku penerimaan teknologi informasi yang diantaranya adalah theory of reasoned action (tra) (fishbein \& ajzen, 1977), theory of planned behaviour (tpb) (ajzen, 1991), technology acceptance model (tam) (davis, 1986), tam2 (venkatesh \& davis, 2000), unified theory of acceptance and use of technology (utaut) (venkatesh et al., 2003) and the extended unified theory of acceptance and use of technology (utaut2) (venkatesh et al., 2012) [13]. Secara umum pada model yang digunakan adalah menggunakan variable utama yaitu perceived usefulness, perceived ease of use, attitude toward using, behavioral intention to use, actual system use dan external variables yang disesuaikan dengan karakter populasi dan topik penelitian yang diilakukan. 


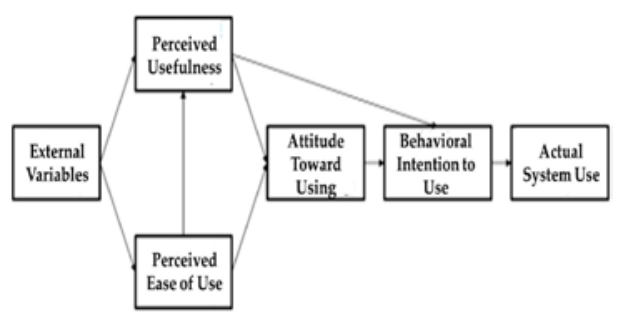

Gambar 1. Technology acceptance model [13]

\section{Metodologi}

Jumlah responden pada penelitian ini adalah sebanyak 165 orang respondent. Teknik pengambilan sample ini adalah menggunakan confidence level dan confidence interval yang menggunakan statistical cochran's significant formula dimana tingkat signifikansi yang digunakan adalah 99\% confidence level dan confidence interval sebesar $10 \%$.

Analisis data akan menggunakan metode regresi linier. Analisis regresi digunaan untuk menguji pengaruh antara setiap variable pada model TAM. Uji regresi yang dilakukan adalah dengan menggunakan uji regresi linier sederhana dan uji regresi linier berganda untuk melihat secara simultan pengaruh pada variable usefulness dan ease of use pada attitude towards using. Pengujian akan dilakukan dengan menggunaan alat uji statistik spss.

Operasional variabel yang akan digunakan pada penelitian ini diambil dari framework model TAM yang digunakan oleh Venkatesh dan davis. Pada model ini akan digunakan sebuah eksternal variabel yaitu variabel cultural (factor budaya).

Cultural (budaya) sebagai External variable. Variabel yang digunakan sebagai eksternal variabel berdasarkan hasil penelitian yang pernah dilakukan oleh junadi dan sferianto yaitu menggunakan indikator akses internet, pengalaman user dalam menggunakan computer dan tingkat Pendidikan [14]. Faktor ini juga pernah diteliti oleh Karimov (2015) yang mengemukakan budaya juga merupakan faktor yang mempengaruhi kesuksesan sebuah usaha ecommerce [15].

Perceived of usefulness. Persepsi Kegunaan yang dirasakan oleh pengguna sistem atau aplikasi yaitu berdasarkan bagimana pengguna merasakan manfaat yang didapatkan dalam membuat peningkatan dalam usaha dan mencapai tujuan yang ditetapkan dengan menggunakan sistem yang ada [16].

Perceived ease of use. Persepsi kemudahan untuk penggunaan sistem didefinisikan sebagai sbeuah kondisi dimana pengguna sistem mudah dlam menggunakan fungsi-fungsi yang terdapat dalam sistem yang mereka gunakan tanpa usaha yang sulit [16] [17]

Attitude toward using. Pengguna sebuah sistem sewajarnya akan memiliki sikap yang menentukan apakah mereka bersikap positive atau negative terhadap sebuah sistem yang mereka gunakan. Sikap ini adalah sebuah konsep penting dalam penelitian sistem informasi. Sikap didefinisikan sebagai evaluasi positif atau negatif terhadap orang, objek acara, kegiatan, ide, atau apa saja di lingkungan [17]

Behavioral Intention to Use. Behavioral Intention to use atau perilaku atas niat pengguna untuk menggunakan sebuah sistem didefinisikan sebagai ukuran terhadap niat sesorang untuk melakukan perilaku tertentu. Niat perilaku mengacu pada kesediaan individu untuk melakukan atau tidak melakukan perilaku tersebut di masa depan secara spesifik. Hal tersebut dianggap sebagai sebuah penting dari perilaku individu [16][17].

Actual system use. Aktualisasi penggunaan sistem informasi atau aplikasi yang telah diberikan kepada pengguna merupakan sebuah hal yang dipengaruhi oleh variabel predictor lainnya seperti intention dan attitude. Actual system use merupakan keadaan dimana pengguna menggunakan sistem yang sudah disediakan dan secara konsisten menggunakan sistem tersebut sebagai sebuah alat dalam setiap kegiatan dengan dasar bahwa hal itu berguna dan tidak membuat rumit pekerjaan. yang dilakukan. Pada penelitian yang dilakukan oleh mboge di afrika pada populasi pelaku usaha mikro juga menyatakan bahwa penggunaan mobile payment juga berpengaruh pada usaha mereka [18] [19].

Hipotesis penelitian yang ditetapkan pada penelitian ini adalah sebagai berikut:

1. H1: Culture berpengaruh pada perceived of usefulness

2. H2: Culture berpengaruh pada perceived ease of use

3. H3: Perceived of usefulness berpengaruh pada attitude towards using

4. H4: Perceived ease of use berpengaruh pada attitude toward using 
5. Perceived of usefulness dan perceived ease of use berpengaruh pada attitude towards using

6. H5: Attitude towards using berepengaruh pada behavioral intention to use

7. H6: behavioral intention to use berpengaruh pada actual system use.

\section{Pembahasan}

\section{Profil Respnden.}

Jumlah responden yang terlibat pada penelitian ini yait 165 orang pelaku usaha umkm di kota Batam. Pada profil responden yang dukumpulkan ditemukan bahwa sebanyak 24,8\% responden telah menggunakan sistem pembayaran digital selama kurang dari 2 tahun dimana angka ini adalah yang terbanyak. Pengguna sistem pembayaran digital yang sudah menggunakan selama 3 tahun sebanyak 24\%, kemudian penggunaan 4 tahun sebanyak lebih dari 5 tahun dan $18 \%$ selama kurang dari satu tahun
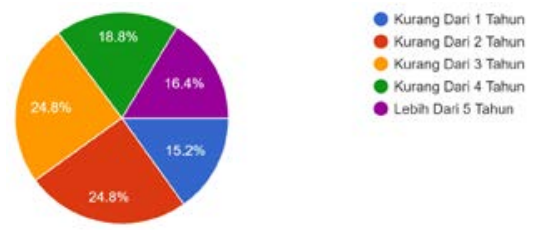

Gambar 2. Penggunaan digital payment

Gateway pembayaran yang digunakan oleh pelaku umkm di kota batam juga ada beberapa jenis pembayaran seperti terlihat pada gambar 3. Pada gambar tersebut terlihat bahwa mobile banking merupakan jenis pembayaran yang paling banyak digunakan oleh responden yaitu $80,6 \%$ dari seluruh responden, kemudian diikuti oleh internet banking sebanyak 55.8\%, kemudian pembayaran berbasis aplikasi mobile sebanyak 30.3\%, dan electronic payment sebanyak $12.7 \%$.

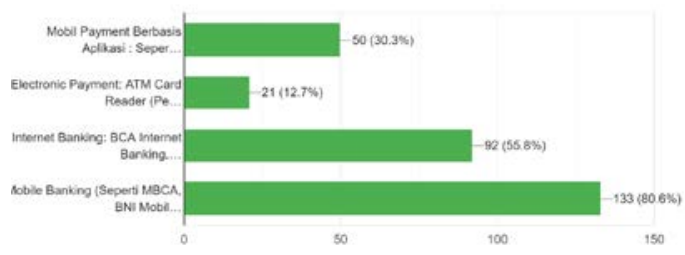

Gambar 3. Gateway pembayaran pelaku umkm

\section{Uji Validitas dan Uji Reliablitas.}

Uji validitas pada penelitian ini menggunakan uji validitas Cronbach alpha. Hasil uji validitas terlihat pada table 1 dimana seluruh nilai variable adalah lebih besar dari 0,6 yaitu nilai minimum dari validitas sebuah variable menurut uji cronbach alpha.

Tabel 1. Hasil uji validitas data

\begin{tabular}{|l|r|}
\hline & \multicolumn{2}{|l|}{$\begin{array}{l}\text { Cronbach's } \\
\text { Alpha if Item } \\
\text { Deleted }\end{array}$} \\
\hline Cu1 & .945 \\
\hline Cu2 & .944 \\
\hline Cu3 & .942 \\
\hline PoU1 & .943 \\
\hline PoU2 & .943 \\
\hline PoU3 & .944 \\
\hline PEoU1 & .945 \\
\hline PEoU2 & .944 \\
\hline PEoU3 & .944 \\
\hline ATU1 & .944 \\
\hline ATU2 & .944 \\
\hline BitU1 & .943 \\
\hline BitU2 & .944 \\
\hline BitU3 & .943 \\
\hline AU1 & .942 \\
\hline AU2 & .943 \\
\hline AU3 & .944 \\
\hline
\end{tabular}

Uji reliabilitas adalah menggunakan uji pearson correlation dapat dilihat pada table 2 . Data pada table 2 terlihat bahwa nilai seluruh variable adalah lebih besar dari nilai minimum pada uji reliabilitas dengan metode uji alpha yaitu 0.3 .

Tabel 2. Hasil uji reliablitas

\begin{tabular}{|l|r|}
\hline Variable & Nilai \\
\hline Cu1 & $.477^{* *}$ \\
\hline Cu2 & $.410^{* *}$ \\
\hline Cu3 & $.586^{* *}$ \\
\hline PoU1 & $.479^{* *}$ \\
\hline PoU2 & $.550^{* *}$ \\
\hline PoU3 & $.545^{* *}$ \\
\hline PEoU1 & $.487^{* *}$ \\
\hline PEoU2 & $.507^{* *}$ \\
\hline PEoU3 & $.472^{* *}$ \\
\hline ATU1 & $.516^{* *}$ \\
\hline ATU2 & $.402^{* *}$ \\
\hline BitU1 & $.558^{* *}$ \\
\hline BitU2 & $.530^{* *}$ \\
\hline BitU3 & $.542^{* *}$ \\
\hline AU1 & $.556^{* *}$ \\
\hline AU2 & $.499^{* *}$ \\
\hline AU3 & $.480^{* *}$ \\
\hline
\end{tabular}




\section{Uji Regresi Data Penelitian}

Pengujian data penelitian yang telah terkumpul pada penelitian untuk melihat hasil penelitian adalah menggunakan uji regresi pada setiap variabel penelitian yang telah ditentukan. Uji regresi sederhana yang dilakukan menghasilkan table summary sebagai berikut.

Tabel 3. Regresi linier variabel Culture terhadap Perceved of usefulness

Model Summary

\begin{tabular}{|l|c|r|r|c|}
\hline Model & $R$ & R Square & $\begin{array}{c}\text { Adjusted R } \\
\text { Square }\end{array}$ & $\begin{array}{c}\text { Std. Error of the } \\
\text { Estimate }\end{array}$ \\
\hline 1 & $.764^{\mathrm{a}}$ & .584 & .581 & 1.38845 \\
\hline
\end{tabular}

a. Predictors: (Constant), PoU_Total

Tabel 4. Regresi linier variabel culture terhadap Perceived ease of use

Model Summary

\begin{tabular}{|l|c|r|r|c|}
\hline Model & $\mathrm{R}$ & $\mathrm{R}$ Square & $\begin{array}{c}\text { Adjusted R } \\
\text { Square }\end{array}$ & $\begin{array}{c}\text { Std. Error of the } \\
\text { Estimate }\end{array}$ \\
\hline 1 & $.723^{\mathrm{a}}$ & .523 & .520 & 1.48631 \\
\hline
\end{tabular}

a. Predictors: (Constant), PEoU_Total

Tabel 5. Regresi linier variabel perceived of usefulness terhadap attitude towards using

Model Summary

\begin{tabular}{|l|c|r|r|c|}
\hline Model & $\mathrm{R}$ & $\mathrm{R}$ Square & $\begin{array}{c}\text { Adjusted R } \\
\text { Square }\end{array}$ & $\begin{array}{c}\text { Std. Error of the } \\
\text { Estimate }\end{array}$ \\
\hline 1 & $.673^{\mathrm{a}}$ & .453 & .449 & 1.53301 \\
\hline
\end{tabular}

a. Predictors: (Constant), ATU_Total

Tabel 6. Regresi linier variabel perceived ease of use terhadap attitude towards using

Model Summary

\begin{tabular}{|l|c|r|r|c|}
\hline Model & $\mathrm{R}$ & $\mathrm{R}$ Square & $\begin{array}{c}\text { Adjusted R } \\
\text { Square }\end{array}$ & $\begin{array}{c}\text { Std. Error of the } \\
\text { Estimate }\end{array}$ \\
\hline 1 & $.647^{\mathrm{a}}$ & .418 & .415 & 1.52412 \\
\hline
\end{tabular}

a. Predictors: (Constant), ATU_Total

Tabel 7. Regresi linier variabel attitude toward using terhadap intention to use

\begin{tabular}{|l|c|r|r|c|}
\hline Model & R & R Square & $\begin{array}{c}\text { Adjusted R } \\
\text { Square }\end{array}$ & $\begin{array}{c}\text { Std. Error of the } \\
\text { Estimate }\end{array}$ \\
\hline 1 & $.693^{\mathrm{a}}$ & .481 & .478 & 1.02807 \\
\hline
\end{tabular}

a. Predictors: (Constant), BitU_Total
Tabel 8. Regresi linier variabel behavior intention to use terhadap actual use

\begin{tabular}{|l|c|r|r|c|}
\hline Model & $\mathrm{R}$ & $\mathrm{R}$ Square & $\begin{array}{c}\text { Adjusted R } \\
\text { Square }\end{array}$ & $\begin{array}{c}\text { Std. Error of the } \\
\text { Estimate }\end{array}$ \\
\hline 1 & $.827^{\mathrm{a}}$ & .685 & .683 & 1.08138 \\
\hline
\end{tabular}

a. Predictors: (Constant), AU_Total

Tabel 8. Regresi linier berganda perceived of usefulness dan ease of use terhadap attitude towars using

Model Summary

\begin{tabular}{|l|c|r|r|c|}
\hline Model & $\mathrm{R}$ & $\mathrm{R}$ Square & $\begin{array}{c}\text { Adjusted R } \\
\text { Square }\end{array}$ & $\begin{array}{c}\text { Std. Error of the } \\
\text { Estimate }\end{array}$ \\
\hline 1 & $.711^{\mathrm{a}}$ & .506 & .500 & 1.00613 \\
\hline
\end{tabular}

a. Predictors: (Constant), PEoU_Total, PoU_Total

Berdasarkan hasil pengujian data yang telah terkumpul dan dilakukan pengujian menggunakan regresi linier sederhana dan berganda maka dapat dilihat bahwa seluruh variabel yang ada pada model TAM dalam sistem pembayaran digital saling berkorelasi satu sama lain.

\section{Uji Hipotesis}

Pada penelitian ini ditetapkan beberapa hipotesis penelitian. Setiap hipotesis tersebut harus dibuktikan apakah diterima atau ditolak dengan menggunakan data penelitian yang telah dikumpulkan. Pengujian hipotesis dilakukan dengan menggunakan table Anova pada hasil regresi yang telah dilakukan. Berikut merupakan pengujian setiap hipotesis penelitian yang ada.

1) Uji hipotesis H1: Culture berpengaruh pada perceived of usefulness

Tabel 9. Nilai sig Culture, perceived of usefulness

\begin{tabular}{|l|r|r|r|c|c|}
\multicolumn{7}{|c|}{ ANOVA $^{\mathrm{a}}$} \\
\hline Model & Sum of Squares & \multicolumn{1}{c|}{ df } & Mean Square & F & Sig. \\
\hline Regression & 440.983 & 1 & 440.983 & 228.751 & $.000^{\mathrm{b}}$ \\
1 Residual & 314.229 & 163 & 1.928 & & \\
\multicolumn{1}{|c|}{ Total } & 755.212 & 164 & & & \\
\hline
\end{tabular}

a. Dependent Variable: CU_Total

b. Predictors: (Constant), PoU_Total

Berdasarkan nilai sig yaitu 0.000 pada table anova diatas maka dapat disimpulkan bahwa H1 diterima. Hasil uji tersebut menyatakan bahwa culture berpengaruh terhadap perceived of usefulness. 
2) H2: Culture berpengaruh pada perceived ease of use.

Tabel 10. Nilai sig Culture, perceived ease of use

\begin{tabular}{|c|r|r|r|c|c|}
\hline Model & Sum of Squares & \multicolumn{1}{c|}{ df } & Mean Square & F & Sig. \\
\hline Regression & 395.127 & 1 & 395.127 & 178.863 & $.000^{\mathrm{b}}$ \\
1 Residual & 360.085 & 163 & 2.209 & & \\
Total & 755.212 & 164 & & & \\
\hline
\end{tabular}

a. Dependent Variable: $\mathrm{CU}$ _Total

b. Predictors: (Constant), PEoU_Total

Berdasarkan nilai sig yaitu 0.000 pada table anova diatas maka dapat disimpulkan bahwa $\mathrm{H} 2$ diterima. Hasil uji tersebut menyatakan bahwa culture berpengaruh terhadap perceived ease of use.

3) H3: Perceived of usefulness berpengaruh pada attitude towards using

Tabel 11. Nilai sig perceived of usefulness, attitude towards using

\begin{tabular}{|l|r|r|r|c|c|}
\hline Model & Sum of Squares & df & Mean Square & F & Sig. \\
\hline Regression & 316.723 & 1 & 316.723 & 134.768 & $.000^{\mathrm{b}}$ \\
1 Residual & 383.071 & 163 & 2.350 & & \\
Total & 699.794 & 164 & & & \\
\hline
\end{tabular}

a. Dependent Variable: PoU_Total

b. Predictors: (Constant), ATU_Total

Berdasarkan nilai sig yaitu 0.000 pada table anova diatas maka dapat disimpulkan bahwa H3 diterima. Hasil uji tersebut menyatakan bahwa perceived of usefulness berpengaruh terhadap attitude towards using.

4) H4: Perceived ease of use berpengaruh pada attitude toward using

Tabel 12. Nilai sig perceived ease of use, attitude towards using

\begin{tabular}{|c|r|r|r|c|c|}
\hline Model & Sum of Squares & \multicolumn{1}{c|}{ df } & Mean Square & F & Sig. \\
\hline Regression & 272.063 & 1 & 272.063 & 117.120 & $.000^{\mathrm{b}}$ \\
1 Residual & 378.640 & 163 & 2.323 & & \\
Total & 650.703 & 164 & & & \\
\hline
\end{tabular}

a. Dependent Variable: PEoU_Total

b. Predictors: (Constant), ATU_Total

Berdasarkan nilai sig yaitu 0.000 pada table anova diatas maka dapat disimpulkan bahwa H4 diterima. Hasil uji tersebut menyatakan bahwa perceived ease of use berpengaruh terhadap attitude towards using.

5) Perceived of usefulness dan perceived ease of use berpengaruh pada attitude towards using.

Tabel 13. Nilai sig perceived of usefulness, attitude towards using

\begin{tabular}{|l|r|r|r|c|c|}
\hline Model & Sum of Squares & \multicolumn{1}{c|}{ df } & Mean Square & F & Sig. \\
\hline Regression & 167.912 & 2 & 83.956 & 82.937 & $.000^{\mathrm{b}}$ \\
1 Residual & 163.991 & 162 & 1.012 & & \\
Total & 331.903 & 164 & & & \\
\hline
\end{tabular}

a. Dependent Variable: ATU_Total

b. Predictors: (Constant), PEoU_Total, PoU_Total

Berdasarkan nilai sig yaitu 0.000 pada table anova diatas maka dapat disimpulkan bahwa H5 diterima. Hasil uji tersebut menyatakan Perceived of usefulness dan perceived ease of use berpengaruh pada attitude towards using.

6) H5: Attitude towards using berepengaruh pada behavioral intention to use

Tabel 14. Nilai sig attitude towards using, behavioral intention to use

\begin{tabular}{|c|r|r|r|c|c|}
\hline Model & Sum of Squares & \multicolumn{1}{c|}{ df } & Mean Square & F & Sig. \\
\hline Regression & 159.625 & 1 & 159.625 & 151.028 & $.000^{\mathrm{b}}$ \\
1 Residual & 172.278 & 163 & 1.057 & & \\
\multicolumn{1}{|c|}{ Total } & 331.903 & 164 & & & \\
\hline
\end{tabular}

a. Dependent Variable: ATU_Total

b. Predictors: (Constant), BitU_Total

Berdasarkan nilai sig yaitu 0.000 pada table anova diatas maka dapat disimpulkan bahwa H6 diterima. Hasil uji tersebut menyatakan Attitude towards using berepengaruh pada behavioral intention to use.

7) H6: Behavioral intention to use berpengaruh pada actual system use.

Tabel 14. Nilai sig behavioral intention to use, actual use

\begin{tabular}{|l|r|r|r|c|c|}
\hline Model & Sum of Squares & df & Mean Square & F & Sig. \\
\hline Regression & 413.973 & 1 & 413.973 & 354.010 & $.000^{\circ}$ \\
1 Residual & 190.609 & 163 & 1.169 & & \\
Total & 604.582 & 164 & & & \\
\hline
\end{tabular}
a. Dependent Variable: BitU_Total
b. Predictors: (Constant), AU_Total

Berdasarkan nilai sig yaitu 0.000 pada table anova diatas maka dapat disimpulkan bahwa H7 diterima. Hasil uji tersebut menyatakan Behavioral intention to use berpengaruh pada actual system use.

\section{Kesimpulan}

Pelaku usaha mikro kecil dan menengah di kota Batam telah menggunakan sistem pembayaran digital berbasis beberapa gateway. Sistem pembayaran yaitu menggunakan sistem pembayaran berbasis mobile, internet dan elektronik dan bahkan ada yang menggunakan 
beberapa jenis pembayaran oleh pelaku umkm di kota Batam. Berdasarkan profil responden pada penelitian ini dilihat bahwa lama penggunaan seluruh responden lebih dari satu tahun yang dapat diartikan bahwa fasilitas yang tersedia di kota Batam digunakan dengan optimal.

Budaya masyarakat kota Batam khususnya pelaku umkm masih memberikan pengaruh yang signifikan terhadap penerimaan teknologi pembayaran digital namun jika menggunakan data yang telah diolah pada penelitian ini dapat dikatakan bahwa pelaku usaha umkm di kota Batam telah mampu menerima teknologi yang lebih modern seperti sistem pembayaran digital tersebut. Penelitian ini juga didukung oleh beberapa penelitian terdahulu yang telah dilakukan seperti di afrika [18], di Malaysia [20] dan juga di Indonesia sendiri [21].

\section{Ucapan Terima Kasih}

Penulisa mengucapkan terima kasih kepada pihak-pihak yang telah mendukung penelitian ini. Pihak pengelola jurnal CBIS, reviewer artikel, editor dan yang lainnya terlibat. Penulis juga sangat memberikan apresiasi kepada seluruh pelaku umkm di kota Batam yang telah bersedia ikut dalam penelitian ini.

\section{Daftar Pustaka}

[1] Bank Indonesia, "Jumlah Uang Elektronik Beredar,” no. 11. p. 2017, 2018.

[2] APJII, "Penetrasi \& Perilaku Pengguna Internet Indonesia 2017,” Asos. Penyelenggara Jasa Internet Indones., pp. 1-39, 2017.

[3] B. K. Batam, "Kota Batam Dalam Angka 2016,” Batam, 2016.

[4] UU No. 20 Tahun 2008, "Peraturan Menteri,” UU No. 20 Tahun 2008, no. 1, pp. 1-31, 2008.

[5] Bank Indonesia, "Statistik," Statistik Sistem Pembayaran, 2018. .

[6] K. Suma Vally and K. Hema Divya, “A Study on Digital Payments in India with Perspective of Consumer"s Adoption," Int. J. Pure Appl. Math., vol. 119, no. 15, pp. 1259-1267, 2018.

[7] R. USMAN, "Karakteristik Uang Elektronik Dalam Sistem Pembayaran,”
Yuridika, vol. 32, no. 1, p. 134, 2017.

[8] L. Klapper, "How digital payments can benefit entrepreneurs," IZA World Labor, pp. 1-9, 2017.

[9] U. Telkom and D. Kolot, “Adopsi teknologi belanja,” pp. 19-38.

[10] R. Tazkiyyaturrohmah, “Transaksi Keuangan Modern,” vol. d, no. November 2016, pp. 21-39.

[11] A. N. Hidayanto, L. S. Hidayat, P. I. Sandhyaduhita, and P. W. Handayani, "Examining the relationship of payment system characteristics and behavioural intention in e-payment adoption: a case of Indonesia,” Int. J. Bus. Inf. Syst., vol. 19, no. 1, p. 58, 2015.

[12] G. Company, "Easier payment with gopay,” 2018. .

[13] E. T. Lwoga and N. B. Lwoga, "User acceptance of mobile payment: The effects of user-centric security, system characteristics and gender," Electron. $J$. Inf. Syst. Dev. Ctries., vol. 81, no. 1, pp. 1-24, 2017.

[14] Junadi and Sfenrianto, "A Model of Factors Influencing Consumer's Intention to Use E-payment System in Indonesia,” Procedia Comput. Sci., vol. 59, no. Iccsci, pp. 214-220, 2015.

[15] F. P. Karimov, "Factors Influencing ECommerce Growth: A Comparative Study of Central Asian Transition Economies," Int. J. E-Adoption, vol. 3, no. 4, pp. 29-43, 2011.

[16] H. M. Abu-dalbouh, “A Questionnaire Approach Based on the Technology Acceptance Model for Mobile Tracking on Patient Progress Applications,” vol. 9, no. 6, pp. 763-770, 2013.

[17] M. J. Alsamydai, "Adaptation of the Technology Acceptance Model (TAM) to the Use of Mobile Banking Services," no. 2014, pp. 2016-2028, 2016.

[18] M. Mbogo, "The Impact of Mobile Payments on the Success and Growth of Micro-Business: The Case of M-Pesa in Kenya,” J. Lang. Technol. Entrep. Africa, vol. 2, no. 1, pp. 182-203, 2010.

[19] E. M. W. Ng, R. H. Shroff, and L. Cher Ping, “Applying a Modified Technology 
Acceptance Model to Qualitatively Analyse the Factors Affecting EPortfolio Implementation for Student Teachers' in Field Experience Placements," Issues Informing Sci. Inf. Technol., vol. 10, pp. 355-365, 2013.

[20] Y. P. Mun, H. Khalid, and D. Nadarajah, “Millennials' Perception on Mobile
Payment Services in Malaysia,” Procedia Comput. Sci., vol. 124, pp. 397-404, 2017.

[21] N. Azilani, Y. Adibrata, and Y. Clement, "Usaha Mikro Kecil dan Menengah di Desa Kopo,” vol. 1. 